\title{
Consideraciones funcionales del acto pedagógico. Consecuencias éticas desde la lectura de Jacques Rancière y Francisco Varela
}

\author{
Elton Zepeda ${ }^{1}$
}

\begin{abstract}
Resumen
Indagando en la mirada de algunos autores, nos sumergiremos en unos cuantos aspectos que competen al acto pedagógico, para entregar evidencia sobre la funcionalidad ${ }^{2}$ o no de su desempeño en el aula. Proponiendo un examen desde conceptos como "extensión", "atención", "potencia intelectual" y "conciencia" inteligente, iremos hilando un sendero para advertir factores que nos sugieran tomar conciencia respecto al acto epistémico. Sin embargo, algunos autores, en sus obras, proponen un fin mayor, un proyecto ético derivado de estos elementos nombrados que, por medio de la educación, encuentran la posibilidad de incidir bienhechoramente sobre la sociedad. Profundizando aún más, se presenta aquí una mirada ética como finalidad intrínseca al acto pedagógico.
\end{abstract}

Palabras clave: extensión - atención - funcionalidad - acto pedagógico - ética

\section{Functional Considerations of the Pedagogical Act Ethical Consequences from a Reading of Jacques Rancière and Francisco Varela Elton Zepeda}

\begin{abstract}
When researching the perspective of some authors, we immersed ourselves in a few aspects of the pedagogical act, in order to provide evidence on the functionality 2 or not of its performance in the classroom. Proposing an examination based on concepts such as "outreach," "attention," "intellectual prowess," and intelligent "awareness," we will trace a path that highlights the factors which suggest that we gain awareness of
\end{abstract}

1 Chileno, estudiante de pregrado de la Universidad Católica Silva Henríquez, Chile. Contacto: elton.zepeda@gmail.com

2 Entendida esta palabra en su aspecto funcional, indicada en la RAE como: dicho de una obra o de una técnica: eficazmente adecuada a sus fines. Estos fines, buscados a lo largo del trabajo, atendiendo a la autonomía y emancipación de los estudiantes. 
the epistemic act. However, some authors propose a greater purpose, an ethical project derived from the abovementioned elements which, through education, make it possible to beneficially impact society. Going even further, this paper presents an ethical perspective as the intrinsic purpose of the pedagogical act

Keywords: outreach - attention - functionality - pedagogical act - ethics

\title{
Considerações funcionais do ato pedagógico. Consequências éticas desde a leitura de Jacques Rancière e Francisco Varela Elton Zepeda
}

\begin{abstract}
Resumo
Indagando sobre o ponto de vista de alguns autores, nos submergiremos em alguns aspectos que competem ao ato pedagógico, para fornecer evidência sobre a funcionalidade ou não de seu desempenho em sala de aula. Propondo uma análise desde conceitos como "extensão", "atenção", "potência intelectual" e "consciência" inteligente iremos traçando um caminho para alertar sobre fatores que nos sugiram tomar consciência com relação ao ato epistêmico. No entanto, alguns autores, em suas obras, propõem un objetivo maior, um projeto ético derivado destes elementos citados que, através da educação, encontram a possibilidade de incidir positivamente sobre a sociedade. Aprofundando ainda mais, apresenta-se aqui um olhar ético como finalidade intrínseca ao ato pedagógico.
\end{abstract}

Palavras-chave: extensão - atenção - funcionalidade - ato pedagógico - ética

\section{Introducción}

La importancia de una interpretación adecuada del fenómeno educativo es una consideración que incumbe la atención no solo de los docentes ahora en formación, sino de todos los actores sociales, como forma de reflexión colectiva sobre un fenómeno tan significativo para el desarrollo humano, dada, también, la urgencia que expone la insustancial actividad ética dentro del mismo acto.

El presente trabajo se encumbra desde una doble mirada (teórica y práctica) basadas en dos autores, cuya relación converge buscando la interpretación de una mirada fenomenológica de la cual se extraerá una lectura adecuada, derivada de tal ejercicio, exponiendo las cuestiones inherentes al ámbito educativo y siguiendo el rastro de una interro- 
gante: ¿es funcional el curso actual del acto pedagógico? Aunque no nos quedaremos en esto, ya que iremos en busca del trasfondo ético al que los autores nos dirigen y que nos impele a realizar este trabajo.

Para su desarrollo — con lo cual me permitirá entrar en el campo docente- investigaré, principalmente, los planteamientos de J. Rancière y Francisco Varela. A partir de la lectura y reflexión sobre ambos, y la exposición atingente de otros, iré exponiendo sucesiones de ideas que confluyen en tres ejes simultáneos: extensión, atención y potencia intelectual de Rancière, y extensión, atención y conciencia inteligente de Varela. Para complementar una mirada más acabada, me ayudaré en otros conceptos que Varela propone como relevantes para la tarea, y que decantan en una reflexión ética sobre los elementos pedagógicos aquí presentados.

\section{Discusión temática}

Primero, como es propio, expondré una definición del acto pedagógico según ambos autores, para establecer el punto de partida de este trabajo.

Rancière expande el fenómeno educativo más allá del aula y, es más, la real dimensión de este acto pedagógico —indica— - viene a plantearse en el seno del hogar, la comunidad, la sociedad, extendiéndose fuera de los lindes áulicos. También Varela asume este compromiso en sus planteamientos sobre lo que, para él, significa acto pedagógico. Varela nos sumerge en un hondo horizonte que, con su intencionalidad, desvela la relevancia del acto pedagógico, solo que acotado a su tratamiento ético. Este "solo", que ha sido mencionado de acuerdo con la acotación de su tema, es retórico, dado que la ética es una base de la cual ningún fenómeno escapa, para manifestar una conducta ya sea pedagógica, social o cultural.

\section{De la funcionalidad del acto pedagógico}

Ya expuestos los pensamientos más generales de los autores, vamos a adentrarnos ahora en el tema que se presenta, exponiendo uno a 
uno los puntos que construirán el entramado para desvelar el grado de funcionalidad del acto pedagógico en la actualidad.

Rancière parte del concepto de "extensión". La extensión es una cualidad importante dentro del aprendizaje, una base o fundamento. Nos indica que, si un maestro enseña a leer un libro, bastará para que el estudiante pueda leer todos los libros existentes y los que puedan existir; a esta habilidad adquirida de expandir lo que se ha aprendido a otros fines de iguales características la denomina "extensión". De no cumplirse el objetivo pedagógico anterior, el estudiante jamás podrá extender sus conocimientos a otros ejercicios paralelos. En cambio, si el acto pedagógico — que no se acota solo al profesor, sino que incluye al padre de familia u otros- es bien guiado, consiguiendo con ello ser eficiente, entregará autonomía al estudiante sobre todas las lecturas futuras. Veamos cómo Rancière se refiere a este acto:

Un libro que es un todo; un centro al cual es posible vincular todo lo que se aprenderá de nuevo; un círculo en el cual se puede comprender cada una de estas cosas nuevas, encontrar los medios para decir lo que se ve, lo que se piensa, lo que se hace. Este es el primer principio de la enseñanza universal: es necesario aprender alguna cosa y relacionar con ella todo el resto. Primero hay que aprender alguna cosa, ¿La Palice diría lo mismo? La Palice quizá, pero el Viejo dice: es necesario aprender tal cosa, y después tal otra y tal otra. Selección, progresión, incompletitud, tales son sus principios (2002 15-16).

Debemos señalar lo fundamental de propiciar esta habilidad, a saber: la extensión. Sin embargo, existe un factor que en su desarrollo cotidiano dentro del acto pedagógico mengua esta habilidad, factor que es llamado "explicación".

Al ser esta explicación un principio fundamental, dentro del acto pedagógico, interfiere en el buen desarrollo del estudiante, dificultando una autonomía que podría ser interiorizada y que se escapa por la desmedida intervención del profesor. Respecto de esta desmedida 
acción explicativa nos advierte también Gastón Beraldi (2009 6): "Ahora bien, esta necesidad de inversión metodológica revela una sospecha. ¿Cuál?: que explicar algo a alguien es demostrarle que no puede comprender solo, que necesita de un sabio que ilumine al ignorante" (Rancière 2006 10).

Lo anterior revela que la intención del profesor, a través de la explicación como reproducción metódica, es consolidar su jerarquía, acción que cristaliza la dependencia de los estudiantes hacia los educadores. Es así que la explicación es la esencia del acto epistémico, encarnada en el proceso educativo por parte del profesor, cuestión innegable y transversal que esconde una oscura representación del sistema educativo, cual podemos seguir evidenciando de la mano de la siguiente cita de Gastón Beraldi (2009 6): “¿Qué es lo que genera desconfianza a Jacotot? Que la utilización de la explicación como método de instrucción sea más que un medio; que sea un fin en sí misma, para el sometimiento, para la dominación".

Podríamos seguir cuestionando el actuar docente al ver su íntima vinculación y comunión con el método explicativo, y seguir cuestionándonos su causa. Después de todo, pudimos ser personas más autónomas, quizá nos hubiéramos emancipado antes, doblando la mano a un destino que nos apremia, una interpretación alternativa de la vida en la que estamos sumidos. Bajo esta mirada, hemos sido educados para obedecer $y$, de alguna forma, se atestigua dentro de esta cita: "(...) el paradigma explicativo es y ha sido la herramienta fundamental de trabajo del docente que lo coloca por encima de quien no sabe y necesita de él, de quien no está dotado de ese saber, de esa 'virtud' de poseer el 'poder explicativo' y transmitir sus conocimientos del sabio al ignorante" (Beraldi 2009 7).

Si no hemos avanzado de categoría, la razón es sencilla: el fundamento educativo tropieza sin descanso con el método referido. La lógica del saber, dentro del paradigma educativo, se concreta en el hecho de mantener esta diferencia irreductible: la del maestro, que tiene todas las respuestas, frente al estudiante, que nada sabe; inequidad que no solo se genera dentro del proyecto educativo sino 
en la sociedad, solidificando la distancia entre quienes controlan el saber y otros que no.

Tal hegemonía del maestro explicador no ha sido cuestionada. Somos deudores de un proceso educativo deficiente que, a nuestras expensas, se sigue reproduciendo: demostración fáctica de nuestra incapacidad reflexiva y crítica, fruto de este mismo proceso pedagógico que aquí ponemos en cuestionamiento. Beraldi (2009 7) expone: "(...) la distancia que pretenden reducir la escuela y la sociedad pedagogizada es aquélla de la que ambas viven y que por lo tanto no cesa de reproducir (...)" (Rancière 2002 2).

Aún se desprende una pregunta: ¿por qué causa el profesor no escatima en hacerse prescindible? Si bien esta pregunta no puede ser trabajada a fondo, ya que el presente trabajo no apunta a eso, es legítimo reflexionar al menos sobre el tema. Quizá nuestra condicionada manera de ver el mundo, esperando por una explicación a todo, bajo la lluvia de la incapacidad reflexiva, nos detiene en nuestros pequeños mundos, sin la tentativa siquiera de plantear una mirada paralela a la actual representación pedagógica aquí trabajada.

Continuando con el empeño que nos reúne, veremos otro enfoque, aunque no muy lejano, para ir construyendo este proyecto que nos puede evidenciar algo del escenario pedagógico actual.

Varela nos muestra un camino muy parecido, aunque desde un enfoque filosófico oriental a través de la figura de $\mathrm{Mencio}^{3}$, cuyas reflexiones amplían el contexto, proponiendo un símil conceptual: la extensión.

3 De nombre Ji Mèngkē, que, al ser traducido de forma literal viene a ser Maestro Meng, conocido en occidente como Mencio, perteneciente al estado de Zou (actual Shan-Tung), nacido hacia el año 372 a.c.

Mencio plantea en su filosofía, una naturaleza bondadosa del hombre, que se remite principalmente a dos cuestiones fundamentales: el hombre debe cultivarse por medio de la disciplina que lo llevará a actuar con buena conducta, o, en caso contrario, este mismo hombre podrá perderse en los vicios.

Varela, utiliza algunas nociones de este pensador chino para presentar un enfoque alternativo y poco ortodoxo en el tratamiento de su trabajo biológico-filosófico con vistas a una mirada ética. 
Esta extensión en Varela cumple la misma función, solo que versa sobre el acto ético que, por lo demás, es cauce obligado de este trabajo. La extensión alude a un conocimiento que se va adquiriendo y que, por fuerza, se debe extrapolar o extender a otros actos enmarcados dentro del ámbito educativo, de igual categoría.

Si la extensión no llegase a ser cumplida fielmente, el sujeto ético no logrará alcanzar la habilidad suficiente para poder relacionar un acto bueno con otros de igual índole. $\mathrm{Si}$, en cambio, el sujeto consigue desarrollar la habilidad en el acto extensivo, asegura la eficiencia de sus actos con fines morales. Es desde lo anterior que la preponderancia de este concepto y su ulterior interiorización serán decisivos para los estudiantes, tal como señala Varela:

Según el pensamiento de Mencio, las personas desarrollan vívidamente la virtud cuando extienden su conocimiento y sentimientos desde situaciones en las que una acción determinada se considera correcta hasta otras en las que la acción correcta no está tan clara. Este hecho presupone, claro está, que deseamos extender el conocimiento y los sentimientos (...) Se parte de una situación simple fácilmente manejable y se va extendiendo por irradiación mediante el aprendizaje a situaciones más complejas (2002 51-52).

Al situar el ejemplo de una imposibilidad de extensión, nos hemos de percatar que el profesor, al no estar bien informado o no dirigir correctamente su voluntad para desenvolver eficientemente su papel en el proceso de este aprendizaje, se trasforma en indispensable para el estudiante, tanto en el aspecto académico como en el ético. En principio, el docente incide negativamente en la gradual adquisición de autonomía del estudiante en el campo de las acciones éticas, interfiriendo en la posibilidad de relacionar las acciones correctas en distintos momentos, por ejemplo, a la hora de tomar buenas decisiones en el ámbito social en el que se encuentra inmerso.

La voluntad antes señalada se presenta durante el acto pedagógico cuando el profesor guía la voluntad del estudiante, proponiendo y promoviendo una búsqueda del saber en éste, de manera que, al tiempo, sea la propia voluntad del estudiante la que tome la iniciativa de 
ahondar cada vez más en lo que le interesa. Esta voluntad, que guía a la voluntad, es tarea inherente al profesor y, a la vez, acción intrínseca dentro del proceso educativo. Lo mismo se puede entender de las palabras de Rancière: "Este método de la igualdad era principalmente un método de la voluntad. Se podía aprender solo y sin maestro explicador cuando se quería, o por la tensión del propio deseo o por la dificultad de la situación" (2002 11).

El estudiante quedaba preparado para entrar al campo epistémico, para dar su propia interpretación, dado que la vivencia de un acto pedagógico como el que hemos descrito, en la unidad de extensión y voluntad, le entregaba autonomía para ser artífice de su propia construcción educativa, fortaleciendo una conducta autodidacta.

Nos hemos introducido entre ciertas proposiciones y conceptos; no obstante, para que el mapa se unifique, es lícito hablar en esta primera etapa de otro factor en juego: la inteligencia guiando a la inteligencia. Si anteriormente hablamos de la voluntad guiando a la voluntad, como un aspecto positivo dentro del acto pedagógico, no es así cuando la inteligencia guía a la inteligencia, ya que el profesor o maestro, al pensar por sus estudiantes en el acto repetitivo de las lecciones progresivas sustentadas en la base de la explicación, atenta contra un sano desarrollo de la autonomía en los estudiantes, al depender éstos de la inteligencia del profesor para entender el mundo.

Si lo anterior no es bueno, tampoco lo será un acto pedagógico en el que se consolide la jerarquía de las inteligencias, resultado equívoco de la inteligencia que guía a la inteligencia, estableciendo una diferencia inquebrantable cuyo fundamento se sustenta en la "virtud" del maestro, aquella competencia exclusiva para comprender, concretada en la explicación eterna, método que imprudentemente es negado a los estudiantes. Sobre esto nos ilustra el propio Rancière:

Ahora bien, este niño que ha aprendido a hablar a través de su propia inteligencia y aprendiendo de aquellos maestros que no le explicaban la lengua, empieza ya su instrucción propiamente dicha. A partir de ahora, todo sucederá como 
si ya no pudiese aprender más con ayuda de la misma inteligencia que le ha servido hasta entonces, como si la relación autónoma del aprendizaje con la verificación le fuese a partir de ahora ajena. Entre el uno y la otra, se ha establecido ahora una opacidad. Se trata de comprender y solo esta palabra lanza un velo sobre cualquier cosa: comprender es eso que el niño no puede hacer sin las explicaciones de un maestro (2002 8).

Como vemos, las implicaciones en el acto educativo por medio de la extensión, trabajadas por ambos autores, nos advierten de lo que puede ser la voluntad de un sujeto que dejó de ser anónimo, y pasa a ser un sujeto que constituye el mundo, situándose con una actitud responsable ante el mismo, por medio del acto educativo, extendiendo sus conocimientos como un compromiso inherente del estar en el mundo y como ser histórico que comparte con la humanidad.

Todo lo dicho se puede presentar de la siguiente forma: el profesor que asegura su jerarquía por medio de la explicación como intermediario constante en el ejercicio pedagógico se hace imprescindible para el estudiante, al no quitar su inteligencia de la ecuación pedagógica, acto que solo eterniza y reproduce la ilegítima labor docente. Los estudiantes pierden su poder de autodesarrollo y se aferran cada vez más a la idea de que su propia inteligencia debe ser guiada por otra que, en este caso, es la del maestro.

Un ejemplo cotidiano, como el presentado, revela sin dudas un ejercicio disfuncional del acto pedagógico que se lleva a cabo en las aulas en la actualidad. Para ahondar más en los efectos que estamos presenciando, aunque, teóricamente, podemos agregar lo que piensa otra autora respecto del maestro explicador que se hace imprescindible:

Su propuesta de enseñanza, surgida por azar, se transforma en el 'método de la igualdad', el 'método de la voluntad'. Es posible aprender solo y sin maestro explicador (que no es lo mismo que sin maestro) cuando se quiere, ya sea por la tensión del propio deseo o por la dificultad de la situación (Alliaud 2006 9). 
Hemos observado algunos aspectos inquietantes dentro del acto pedagógico que se deben contemplar para una salida a la tautología de la explicación, proveniente ésta, en gran medida, del concepto "extensión", expuesto con algo de profundidad, dado el grado de incidencia que conlleva en el sano desarrollo del trabajo áulico.

Siguiendo con otra arista concomitante, se encuentra otra etapa en la que confluyen los autores. Rancière presenta un segundo elemento: la atención. El autor, que ha colocado a la vista la extensión, dispone ahora de este elemento tan importante como el anterior. Así, la atención tiene por finalidad entregar el punto de inflexión al estudiante por medio de la visualización de sus actos anteriores de extensión, cuya utilidad radica en que, por medio de la atención, el estudiante da cuenta de qué está haciendo, cómo lo hace y de los actos y hechos que lo llevarán a apropiarse del conocimiento.

Si el estudiante no encuentra un momento propicio para que su atención se agudice, difícilmente podrá llegar a encontrar aquel punto de unión entre el qué y el cómo, para desarrollar sus habilidades epistémicas. De no llegar a potenciar la atención, se perderá un factor de gran importancia que asegurará el aprendizaje en el acto pedagógico mismo, ya que esta capacidad de atención para distinguir los elementos constitutivos que reúne un acto pedagógico le entregará las herramientas para desempeñar al máximo sus competencias. Manteniendo el orden de nuestro trabajo, dejaré a Rancière expresar lo que piensa sobre esto:

(...) no diré que tiene menos éxito porque es menos inteligente. Diré que quizá obtuvo un trabajo menos bueno porque trabajó menos bien, que no vio bien porque no observó bien. Diré que prestó a su trabajo una atención menor. (...) La atención no es ni un bulto del cerebro, ni una cualidad oculta. Es un hecho inmaterial en su principio y material en sus efectos: tenemos mil maneras de comprobar la presencia, la ausencia o la intensidad mayor o menor de la atención (2002 31).

Manteniendo una homonimia mas no sinonimia con lo anterior, será Varela quien, ahora, nos indique el elemento que trata: "la atención". 
La atención es una capacidad de concentración necesaria que requiere el estudiante para entrever los puntos de unión en cada acto ético -más aún, se puede extrapolar esto al campo epistémico, si nos damos cuenta de que todo trata de aprendizaje-, cuya finalidad es advertir los entramados, para luego hacer distinciones y asegurar el conocimiento.

Si el estudiante no lograse una concentración eficiente como para advertir los entramados insertos en el desarrollo del acto pedagógico, jamás podrá llevar a cabo la extensión y, por ende, no aprenderá como es debido. Si, en cambio, el estudiante llega a una buena conclusión sobre la construcción de estos entramados, recaudará la información de manera certera. La atención es fundamental en cuanto a cualidad distintiva dentro de los saberes para apropiarse realmente de ellos. Varela nos dice al respecto:

El proceso [de extensión] da por sentado que los individuos poseen una capacidad para prestar atención a aquello que se debe hacer [...] La capacidad específica de la mente que subyace a todo este proceso es la habilidad para atender [...] La atención insuficiente lleva a una autoeducación mal encaminada (2002 52).

Esta capacidad de atención, recalcada por el autor, deja en evidencia su inherente importancia participativa en el proceso de aprendizaje, y es que, sin la ejecución de esta habilidad, el proceso pedagógico se estanca y, más aún, acarrea negativas consecuencias en la formación de los educandos.

Para evidenciar esto podríamos decir: el profesor, inmerso en la reproducción de su acto pedagógico, no toma en cuenta la importancia de la atención dentro del mismo, dado que solo explica y hace repetir, pero no reflexiona ni subraya los puntos que trata, restando la debida importancia a la atención y a al papel que juega en el proceso. Esta estrategia — preocupante-, presentada en cada institución educativa, se ha encargado de desunir las capacidades y competencias que cada estudiante lleva en potencia. Sin embargo, debemos avanzar y seguir proponiendo los puntos que se enmarcan para encontrar la 
respuesta a la pregunta inicial, a saber: ¿es funcional el curso actual del acto pedagógico?

Rancière propondrá, luego, un concepto primordial, el concepto de "potencia intelectual". Esta cualidad, constitutiva del aprendizaje, cumple un rol protagónico, transformándose en condición necesaria para saber qué se está aprendiendo, asegurando que el acto pedagógico sea eficiente. Por ende, de no poder desarrollar de buena forma esta potencia intelectual, el estudiante se pierde en la confusión de saber cuándo extrapolar sus conocimientos adquiridos sobre la base de un logro de la extensión anterior.

La consecuencia es una confusión epistémica, que se produce cuando el maestro no retira su inteligencia del acto epistémico, en el que constituye como imprescindible su inteligencia sobre la inteligencia del estudiante. Aunque, una vez retirada la inteligencia del profesor de la ecuación intelectual, el estudiante advierte que no necesita de la explicación para conocer el libro: es aquí donde la inteligencia del estudiante despierta. Si el estudiante logra desarrollar propiciamente su potencia intelectual, como factor que incide directamente en su proceso de autoconstrucción pedagógica, asegurará la extensión del conocimiento ya internalizado, así como también hacerse de nuevos saberes en lo futuro. Rancière afirma:

La experiencia le pareció suficiente para entenderlo: se puede enseñar lo que se ignora si se emancipa al alumno, es decir, si se le obliga a usar su propia inteligencia. Maestro es el que encierra a una inteligencia en el círculo arbitrario de donde solo saldrá cuando se haga necesario para ella misma. Para emancipar a un ignorante, es necesario y suficiente con estar uno mismo emancipado, es decir, con ser consciente del verdadero poder del espíritu humano. El ignorante aprenderá solo lo que el maestro ignora si el maestro cree que puede y si le obliga a actualizar su capacidad: círculo de la potencia homólogo a ese círculo de la impotencia que une al alumno con el explicador del viejo método (...) A la inteligencia que dormita en cada 
uno, bastaría decirle: Age quod agis, atiende a lo que estás haciendo, "aprende el hecho, imítalo, conócete a ti mismo, éste es el camino de la naturaleza". Repite metódicamente el método del azar que te ha dado la medida de tu poder. La misma inteligencia obra en todos los actos del espíritu humano (2002 12-13).

Tenemos, además, que la experiencia dentro del acto epistémico se transforma en vital, cual praxis anticipada de un autodesarrollo, ya que es la única forma en que el estudiante, inmerso en el ejercicio, podrá advertir, por medio de la potencia intelectual a modo de conciencia, cómo funcionan la extensión y atención para graficar, a modo de meta aprendizaje, el método que lo llevará a su emancipación.

El mismo Varela propone, de modo similar, una segunda instancia luego de la extensión, que funciona de igual forma, pero en un ámbito diferente, llamada: "conciencia inteligente". Ésta tiene la finalidad de fijar los conocimientos, haciendo que el sujeto ético se dé cuenta de lo que aprende. El autor manifiesta que, si bien la extensión es un asunto relevante, sin el adecuado análisis de lo que se hace, el acto pedagógico cotidiano no llegará a ser actualizado por completo. De otro modo, si esta consciencia es eficiente, los aprendizajes que han tenido lugar serán bien construidos y desarrollados por el estudiante. Respecto de esto, Varela indica: "Esos individuos no actúan a partir de la ética, sino que la corporeizan como cualquier experto corporeiza su conocimiento" (2002 57).

Por lo anterior, la formación desde la primera infancia es un desafío que debemos resolver situándonos desde estas perspectivas, lejanas a nuestra cultura occidental y, por extensión, a nuestra tentativa educacional, dado que el punto de inflexión que antecede a un acto moral es reflexivo y no instintivo, como ocurre en la tradición budista, cuyo principio funciona no en base a reflexiones aisladas que anteceden al acto moral, sino como una preparación desde la primera edad para que la decisión que se lleve a cabo no se estanque en la reflexión, al contrario, exige una corporeización de la ética como virtud, siendo, como dice Mencio a través de la voz de Varela: 
(...) solo los que actúan desde las disposiciones en las que se encuentran en el mismo momento de la acción como resultado de un largo proceso de autocultivación merecen el apelativo de virtuosos. Se puede decir que esas personas han actuado con benevolencia y rectitud; no es que hayan puesto en funcionamiento la benevolencia y la rectitud (2002 56-57).

Se visualiza ahora que el papel pedagógico del profesor occidental se encuentra "atrapado" dentro de un quehacer o acto pedagógico que no puede romper sus propios límites sin antes abrir sus fronteras y readecuarlas. Así, Varela nos advierte que: "Aquellos individuos que actúan según los patrones de respuesta habituales en lugar del empleo de la conciencia inteligente no perciben las situaciones adecuadamente" (2002 56). Esto es un directo reflejo del tipo de educación mecánica y basada en la memorización, que persiste y resiste en nuestro sistema educativo, lejana a la didáctica empírica que se necesita.

La relación coexistente entre la extensión y potencia intelectual, por un lado, y la conciencia inteligente, por otro, se presentan en un hecho vital en el momento mismo de la concreción del aprendizaje, en el que lo aprehendido dará pie a transformarse en conciencia, que viene a responder en la adquisición de conciencia sobre lo que se va conociendo, única premisa para que el acto pedagógico, ya sea ético o epistémico, se interiorice debidamente. Estas cualidades, confluyentes en los autores, son fenomenológicas en cuanto son representativas en el acto in situ, o en cuanto constituyen la vivencia misma en el acto pedagógico.

Veamos, de la mano de las evidencias, cómo se desarrolla el anterior panorama. El profesor, primero, obstruye un libre camino hacia la extensión de los estudiantes — por medio de su explicación eterna: interrupción en la inteligencia del estudiante-; luego, lo hace también con la atención, ya que, sin extensión, no se sigue la correcta atención. Las evaluaciones, en su forma, no cargan un mal auténtico; sin embargo, parten de una base que presenta desventajas. Reflexionando 
sobre este punto, no se necesita un estudio más aplicado, puesto que, si la base sobre la que se presentan los distintos factores que inciden directamente en la construcción del acto educativo es mal trabajada, el cimiento que alberga el acto pedagógico no podrá ser medido correctamente, ya que se pide a los estudiantes pruebas de algo que no han aprehendido durante el proceso educativo.

Una primera conclusión estima que, durante la creación curricular, se planteen objetivos sensatos, entregando una planificación consecuente con lo que se pide en los objetivos, dado que los docentes, en sus esfuerzos por planificar a la par de los planes y programas, ya disfuncionales, dificultan su ejercicio, decantando en cada una de las falencias del acto pedagógico, que resultan ser disfuncionales al igual que los criterios de los cuales emanan. Hasta aquí todo resulta ser una tautología del error, basada en una teleología educativa disfuncional.

La unificación de los elementos que los dos autores nos proponen -y que hemos revisado en paralelo-, nos muestra evidencias de que lo estudiado es, visto desde el acto pedagógico, un fenómeno muy complejo.

Como todo fenómeno tiene elementos que se hilvanan haciendo tejidos conceptuales y vivenciales con orden a un horizonte, que en este caso es pedagógico, la intencionalidad de los elementos dispuestos aquí nos muestra la importancia de hacer un tratamiento más exhaustivo para llegar a comprehender y asirse de este fenómeno.

Expondré ahora algunas consideraciones conceptuales y prácticas de Varela, para ampliar el desarrollo con miras a establecer el grado de funcionalidad del acto pedagógico. El autor nos vuelca a considerar una triada en los conceptos de: "microidentidad", "micromundo" y "enacción" (2002). El tratamiento de estos conceptos nos abrirá otra puerta para comprender de mejor forma el fenómeno que estudiamos aquí, y que nos lleva hacia la concreción de la tarea.

Como hemos visto, se han enunciado los factores que se han de conjugar en el proceso que construye el acto pedagógico, con miras 
a establecer su grado de funcionalidad y, ahora, se desprende casi por ley su alcance ético que trasciende el campo educativo. Todos los elementos aquí evaluados serán la antesala de una mirada ética, como consecuencia insoslayable derivada de una educación que se enmarca como responsabilidad con los educandos y su ulterior repercusión social.

\section{Consecuencias éticas derivadas de la funcionalidad pedagógica}

Nos dice Varela que la microidentidad se presenta en lo cotidiano, es la representación del cómo, el conjunto de significaciones personales, subjetivas, desde las que el sujeto realiza una de las lecturas del mundo. Este antecedente nos revela que no existe una sola manera de relacionarse con el mundo, ni con los demás. Entonces, no escatimar este elemento es crucial y, por ello, es indispensable que sea tratado en todo aspecto pedagógico; por ejemplo, dado que esta microidentidad es la manera que adoptamos para relacionarnos con el mundo, se plantea que un estudiante no tendrá la misma disposición para la clase si está enojado o alegre, o sea, se entabla una disposición dentro del aula que pasa a ser la microidentidad.

Sumaremos a lo anterior el micromundo, la representación del dónde, cuya cualidad espacio-temporal se une irrevocablemente a la microidentidad. La importancia de esto se puede verificar en el espacio aula, pues, el comportamiento y disposición de los estudiantes (microidentidad) no será el mismo en el aula que en sus hogares (micromundo), de lo que se advierte la importancia de una planificación bien contextualizada. Así, el acto pedagógico se debe llevar a cabo desde la microidentidad en un tiempo-espacio que es el micromundo. Cabe señalar que realizamos actos diferenciados de acuerdo con quienes estamos y según dónde estamos. Pero dejemos que Varela sea quien nos cuente más sobre esto:

Cuando nos sentamos a almorzar con un pariente o amigo, participamos en el complicado ritual de la utili- 
zación de los cubiertos o en la conversación de manera inconsciente. Podríamos decir que el "autoalmorzar" que poseemos es transparente. Acabamos el almuerzo, regresamos a la oficina y entramos en un nuevo estado de ánimo que posee su propia manera de hablar, de moverse, de hacer valoraciones. Poseemos una disposición para la acción propia de cada situación específica; además, nos movemos de una a otra constantemente. A menudo, estas transiciones o saltos son débiles y prácticamente imperceptibles; otras veces son abrumadores, como en aquellos en los que nos encontramos el peligro de cara y sin previo aviso. A esta disposición para la acción la llamamos microidentidad y a su correspondiente situación real, micromundo (2002 25).

La cita anterior nos enmarca dentro de un aspecto muy relevante, ya que quienes somos se debate en la conjugación de estos dos factores inmersos en el acto pedagógico, tomando conciencia de que es la identidad del estudiante la que está en juego, cuestión de primer orden, dado que un estudiante que no se conoce a sí mismo, tendrá menos probabilidades de autodesarrollarse y encontrar su emancipación.

Estos dos factores nos llevan a establecer la importancia de otro factor fundamental dentro de lo que estamos trabajando y es la enacción, una cualidad que implica tanto el acto como el conocimiento, transformándose en fundamento vital de nuestras experiencias. Por lo mismo, el acto desplegado en la enacción nos sugiere un despliegue, un estar en el mundo, en los hechos, buscando solución sobre una construcción incesante ante un mundo que se actualiza constantemente.

De los dos factores antes vistos - microidentidad, micromundo- $y$ de la cualidad llamada "enacción" se interpreta el siguiente ejercicio del acto pedagógico: en el aula un saber queda siempre descontextualizado, porque la información entregada no hace converger y ni siquiera contempla, dentro de su didáctica, a los dos factores en tal desarrollo. No hay, por ende, una relación didáctica entre las distintas microidentidades y micromundos que ahí confluyen, por 
lo que la enacción queda fuera, sin poder desplegarse ante el nuevo conocimiento.

Ahora, si entramos en el aspecto fenomenológico, que es otra mirada que se desprende, podemos observar que, en tanto el fenómeno educativo o acto pedagógico es una manifestación ante los sujetos, es obvio que ni la intención del maestro es clara, ni el sujeto estudiante puede describir el sentido del ejercicio incrustado en tal acto, cerrando el horizonte a nuevos conocimientos. No basta que los estudiantes traten de examinar los contenidos de la conciencia, ya que ni uno de los elementos citados más arriba, como tampoco los recién mencionados, son contemplados en el acto pedagógico, cuestión que deja nula tal tarea educativa.

Llegado a este punto, nos queda una desembocadura inherente al río teórico y práctico que hemos trabajado hasta el momento: su trascendencia ética. Si Rancière ha propuesto todo un desarrollo de lo que debería ser el fundamento pedagógico, su idea no se agota en principios o consideraciones educativas, sino que va más allá, convergiendo con un tema de relevancia social: un trasfondo ético. Todos los dardos de la implicancia educativa que él manifiesta llevan la marca de lo que podríamos hacer para que la sociedad sea un lugar más igualitario, proponiendo, lúcidamente, que todas las inteligencias son iguales, por lo que un correcto desempeño y conocimiento del bien podría dar las claves para mejorar la sociedad basadas en la propuesta de igualdad.

Ya visualizados algunos de los elementos constitutivos de su obra y advertida su relevancia, veremos que nos dice el autor respecto de la finalidad social de todo su andamiaje argumentativo:

Los unos piensan que esta desigualdad inevitable contribuye a la diferencia social tal como la variedad infinita de las hojas a la inagotable riqueza de la naturaleza. Tan solo hace falta que ella no impida a la inteligencia inferior comprender sus derechos $y$, sobre todo, sus deberes. Los otros piensan que el tiempo, poco a poco, progresivamente, atenuará esta deficiencia causada por siglos de opresión y oscuridad. En los dos casos, la causa de la igualdad — de la buena igual- 
dad, de la igualdad no funesta - tiene el mismo requisito, la instrucción del pueblo: la instrucción de los ignorantes por los sabios, de los hombres hundidos en las preocupaciones materiales egoístas por los hombres altruistas, de los individuos encerrados en su particularismo por el orden universal de la razón y de los poderes públicos. Eso se llama la instrucción pública, es decir, la instrucción del pueblo empírico programada por los representantes del concepto soberano del pueblo (2002 71)

Existe una profunda relación entre los actos pedagógicos y la finalidad ética, intrínsecamente necesaria, interpretación obligada sobre los múltiples factores que trabajan para llegar a esta finalidad. Rancière aboga por una igualdad que solo se puede lograr si se contemplan los distintos ámbitos que influyen en del acto pedagógico.

Varela, por su parte, de una manera explícita, nos inunda con sus planteamientos en torno a una pedagogía ética. Entonces, no será extraño que, al igual que a lo largo del trabajo, ahora también confluyan estos autores. Varela apelará a una compasión, que nos hace un llamado a estar en el mundo con los otros. Todas sus fuerzas argumentativas hacen salir a flote esta consideración, que implica nada menos que la unión y aceptación de todos por todos, aquella compasión fruto de sentimiento y conocimiento.

Si bien cada uno de los elementos que Varela dispone son direccionados desde una mirada educativa, en cuyo desempeño se advierten planteamientos pedagógicos, su finalidad es sin duda una reflexión sobre cómo podemos mejorar la sociedad. Varela nos dice al respecto:

¿Cómo se puede fomentar e incorporar a nuestra cultura un asunto tan compasivo, tan descentralizado, que abarca tanto? Evidentemente, no se puede hacer mediante la creación de meras normas o preceptos racionalistas, sino que ha de desarrollarse e incorporarse a través de disciplinas que faciliten la liberación de los hábitos egocéntricos y que posibiliten que la compasión se convierta en algo espontáneo y autosuficiente. No quiere esto decir que no exista una 
necesidad de reglas normativas en el mundo relativo, porque reglas hacen falta en cualquier sociedad. Lo que queremos decir es que, a no ser que las reglas se vean impregnadas de la sabiduría que les permita disolverse ante las exigencias sensibles de las particularidades y la inmediatez de una situación real determinada, se tornan estériles y se convierten en obstáculos academicistas para el desarrollo de la acción compasiva, en lugar de verdaderos canales que ayuden a su manifestación (2002 127-128).

Lo planteado por los autores demuestra la implicancia individual y social de la pedagogía junto a su significado actual, quedando en cierta medida una labor pendiente, que consiste en resignificar la pedagogía para que adquiera otra mirada y, por ende, una repercusión positiva en la humanidad. Por lo mismo, es difícil no arriesgarse a la investigación del tema pedagógico y desmontar sus articulaciones como lo hemos venido haciendo. La interrogante realizada al principio acusa en su seno esta implicancia, aunque sin ser explícita.

Hemos de repasar que el elemento de extensión no se cumple, pues no hay extensión si el profesor priva de su autodesarrollo al estudiante durante el acto pedagógico. Por otro lado, ni la potencia intelectual ni la conciencia intelectual tienen lugar para su desarrollo, dado la falta de herramientas críticas y reflexivas en las instancias donde el acto pedagógico tiene lugar. Sumado a todo, la atención, sin el auténtico y completo desarrollo de los dos elementos anteriores, no tiene posibilidad de ser, dado que los tres elementos son correlativos y constitutivos dentro del acto pedagógico.

Por lo demás, el acto que se transforma en pedagógico sugiere una interrelación entre los elementos constitutivos para extrapolar el contexto educativo a la vida, aquella realidad informe que siempre está fluctuando y se quiere bien comprender por medio de una hermenéutica que trasciende a lo epistémico, de lo cual se sigue, como indica Iván Oliva (2010 20), que el fenómeno cognitivo no se basa tanto en la representación, denotación y/o descripción, sino en la cogeneración cognitiva de lo que hemos aprendido a llamar realidad. 
Siguiendo con nuestro análisis, la coherencia y funcionalidad del acto pedagógico, dentro de las instancias hasta aquí revisadas, se plantea como una constante que juzgará cada lector; sin embargo, en cuanto la finalidad de la pedagogía es entregar herramientas y ser-hacer una guía a los estudiantes con miras a la autonomía, está lejos de ser alcanzada a cabalidad, pues es una intervención que no se ha de desarrollar, ni menos presentar en el acto pedagógico de la actualidad.

Sin embargo, el tema no se acaba aquí. Vemos que la intención ética tampoco es trabajada, ni dentro de la didáctica pedagógica aquí expuesta, como tampoco en las finalidades de tales actos. Si apelamos a una interpretación de lo visto, diremos que el andamiaje educativo no contempla la multiplicidad del individuo, así como sus mundos —o micromundos—, dejando de lado una real emancipación de los estudiantes como vía infalible para una mejora de la educación, basada en propuestas de igualdad y compasión, y, por extensión, su ulterior repercusión social: un sano desarrollo ético.

Si bien el trabajo ha propuesto una mirada al acto pedagógico, no es lugar para que el tema se agote ni mucho menos, si realmente creemos que la educación actual debe ser deconstruida. Una mirada fenomenológica sobre el quehacer docente y sus implicancias en los estudiantes a nivel transversal, y en las generaciones que vienen, es, creo, demasiado importante como para que el trabajo presente quede sin profundizar.

Considerar funcional o no el curso actual del acto pedagógico es una respuesta que ustedes mismos deberán dar. Solo he tratado de procurar los datos y hechos que propicien un juicio y, además, queda la esperanza en que nuevas perspectivas, tanto teóricas como prácticas, se lleven a cabo con el fin de mejorar para siempre un sistema a todas luces inadecuado.

\section{Conclusiones}

Sobre la funcionalidad del acto pedagógico, hemos presentado algunos puntos que permitieron tener una idea sobre su ejercicio; sin embargo, nos queda todavía por delante mejorar su tratamiento 
concreto en aula, ya que, si no se pone atajo a su actual desempeño, seguirá su eterna reproducción que, por lo demás, no propicia un buen desarrollo estudiantil ni menos una real emancipación.

Atendiendo al tema ético, nos vimos sumergidos en su ejercicio teórico, cuya relación, junto al análisis del funcionamiento del acto pedagógico, nos revela sus consecuencias ulteriores en la sociedad, dado el grado de unidad existente entre la tarea educativa y su consecutivo desenvolvimiento en la sociedad, responsabilidad ética que debe ser concebida en el acto pedagógico, atendiendo a su incidencia en la esfera sociocultural.

La unicidad entre la educación y el aspecto ético nos exhorta a profundizar sobre la relación entre ambas; primero, para establecer el fundamento de la formación estudiantil que más ampare el entramado de estas miradas y, así, en segunda instancia, reparar en sus repercusiones, que no se agotan en el nivel áulico, sino que escapan de las paredes institucionales, en el despliegue de sus acciones inmersas en el ámbito sociocultural.

Finalmente, sería propicio que el tema no se agote aquí, proponiendo una mirada hermenéutica que profundice aún más en los aspectos ligados a este estudio, investigación futura que podría dar una luz sobre el tema, en busca del perfeccionamiento de la educación y, por añadidura, su futuro desempeño dentro de la sociedad.

\section{Bibliografía}

Alliaud, Andrea. "Experiencia, Narración y Formación Docente", Educação \& Realidade 31 (2006): 7-22.

Beraldi, Gastón. "Rancière y la posibilidad de un 'acontecimiento' político en la educación". Ciencia, Docencia y Tecnología XX/39 (2009): 107-120.

Oliva, Iván. "Breve cartografía de una disonancia epistémica: educación, complejidad y reforma", POLIS Revista Latinoamericana 25 (2012): 20. Recuperado de: http://journals.openedition.org/polis/533

Rancière, Jacques. El Maestro Ignorante. Barcelona: Editorial Laertes, 2002.

Varela, Francisco. La habilidad ética. Barcelona: Debate, 2002. 